LBNL-56257

\title{
PERFORMANCE OF UNDERFLOOR AIR DISTRIBUTION: RESULTS OF A FIELD STUDY
}

\author{
${ }^{1}$ William Fisk, ${ }^{1}$ David Faulkner, ${ }^{1}$ Douglas Sullivan, \\ ${ }^{2}$ Christopher Chao, ${ }^{2}$ Man Pun Wan, \\ ${ }^{3}$ Leah Zagreus, ${ }^{3}$ Tom Webster \\ ${ }^{1}$ Indoor Environment Department \\ Environmental Energy Technologies Division \\ Lawrence Berkeley National Laboratory \\ Berkeley, CA \\ ${ }^{2}$ Department of Mechanical Engineering \\ Hong Kong University of Science and Technology \\ Hong Kong \\ ${ }^{3}$ Center for the Built Environment \\ University of California, Berkeley \\ Berkeley, CA
}

August 31, 2004

This work was supported by the Assistant Secretary for Energy Efficiency and Renewable Energy, Building Technology Program of the U.S. Department of Energy under contract DEAC03-76SF00098. 


\title{
PERFORMANCE OF UNDERFLOOR AIR DISTRIBUTION: RESULTS OF A FIELD STUDY
}

\author{
August 31, 2004
}

William Fisk, David Faulkner, and Douglas Sullivan

Indoor Environment Department, Lawrence Berkeley National Laboratory, Berkeley, CA

Christopher Chao and Man Pun Wan

Department of Mechanical Engineering, Hong Kong University of Science and Technology, Hong Kong

Leah Zagreus, Tom Webster

Center for the Built Environment, University of California, Berkeley, CA

\begin{abstract}
Underfloor air distribution (UFAD) is a new method of supplying heated or cooled air throughout a building. Reported advantages of UFAD include easy relocation of air supply diffusers, energy savings, and improved indoor air quality (IAQ). We measured several aspects of the performance of an UFAD system installed in a medium-size office building. The measured air change effectiveness was very close to unity, which is comparable to that measured in buildings with typical overhead air distribution. The pollutant removal efficiency for carbon dioxide was $13 \%$ higher than expected in a space with well-mixed air, suggesting a $13 \%$ reduction in exposures to occupant generated pollutants. The increase in indoor air temperatures with height above the floor was only 1 to $2{ }^{\circ} \mathrm{C}\left(2-4{ }^{\circ} \mathrm{F}\right)$. This amount of thermal stratification could reduce the sensible energy requirements for cooling of outdoor air by approximately $10 \%$. The occupant's level of satisfaction with thermal conditions was well above average and this high satisfaction rating could possibly be due, in all or part, to the use of a UFAD system. The results of this study provide some evidence of moderate energy and IAQ-related benefits of UFAD. Before general conclusions are drawn, the benefits need to be confirmed in other studies.
\end{abstract}

\section{BACKGROUND}

Underfloor air distribution (UFAD) is a relatively new method of supplying heated or cooled air throughout a building. With UFAD, the building's heating, ventilation, and air conditioning (HVAC) system supplies conditioned air, normally a mixture of recirculated and outdoor air, to the air supply plenum located below a raised floor constructed from floor panels suspended on a grid of pedestals. Supply air registers (also called supply diffusers) are inserted at desired locations in the raised floor by replacing normal floor panels with a floor panels containing a supply diffuser. A more detailed description of UFAD systems is provided by Bauman (2003).

For a number of reasons, the use of UFAD systems is increasing rapidly (Lehrer and Bauman 2003). UFAD air supply diffusers are easy to relocate when the space usage changes. The underfloor plenum eases the routing of wiring. Some UFAD systems have occupant adjustable supply diffusers which provide occupants a degree of individual control of local thermal comfort conditions. Energy savings is 
another motivation for use of UFAD systems. Because UFAD systems supply higher temperature air ${ }^{1}$ than conventional HVAC systems, UFAD increases the opportunity to use outdoor air for free cooling via economizer systems under suitable climatic conditions. Example calculations for a building in San Francisco indicate that there are 2200 additional hours of free cooling per year via an economizer with UFAD versus conventional air distribution (Lehrer and Bauman 2003). The increased supply air temperature can also improve the coefficient of performance of air conditioning systems. Based primarily on laboratory studies, UFAD can also result in a vertical thermal gradient in air temperature within the occupied spaces. As discussed in Appendix 1, the vertical temperature gradient can reduce the energy required for air conditioning. UFAD systems also have less supply air ductwork than conventional overhead systems. Webster et al (2002) estimated that the supply airstream pressures that central supply fans must produce can be reduced by $25 \%$ with UFAD systems, which, in turn, diminishes fan energy use.

An upward displacement ventilation airflow pattern leading to an improvement in ventilation efficiency is another widely reported advantage of UFAD; however, very few relevant data are available. The index used most often to quantify the degree of improvement of ventilation efficiency (ASHRAE 2002) is the air change effectiveness (ACE). The practical interpretation is that the ACE indicates the effective ventilation rate at the breathing zone divided by the ventilation rate that would occur through the indoor space with the same amount of outdoor air supply and perfect mixing of the indoor air. If the ACE is greater than unity, the minimum required rate of outdoor air supply can be reduced (multiplied by 1/ACE) to save energy (ASHRAE 2002). For example, with an ACE of 1.5, the required minimum rate of outside air supply is reduced by one third.

At present, there are very few published data on the values of ventilation efficiency obtained with UFAD systems. Our prior laboratory studies demonstrated that one first-generation UFAD system produced ACE values as high as 1.3, under some operating conditions (Faulkner et al. 1993). However, no prior publications documenting measurements of ventilation efficiency in an actual building with UFAD have been identified. Therefore, a primary objective of this study was to determine whether UFAD in practice results in a ventilation efficiency above unity, implying improved indoor air quality and an opportunity to save energy by reducing the rate of outdoor air supply. Secondary objectives of this study were to add to the limited information on the thermal stratification, occupant satisfaction with thermal conditions, and occupant satisfaction with air quality in buildings with UFAD.

\section{STUDY METHODS}

\section{Study building}

The measurements were performed in a model high performance office building located in Pennsylvania. The building is LEED ${ }^{2}$ Certified (Gold Rating) and incorporates a number of energy efficiency features including high levels of thermal insulation, high performance triple-pane windows, and a window configuration plus light shelves designed to provide a high level of daylight. The building has two stories and a floor area of approximately 3,100 $\mathrm{m}^{2}\left(33,000 \mathrm{ft}^{2}\right)$. The second floor of this building, which contained most of our study sites, has a ceiling height that ranged from $2.9 \mathrm{~m}(9.7 \mathrm{ft})$ at the building

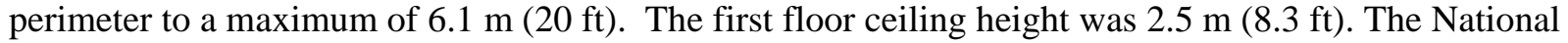
Renewable Energy Laboratory has previously studied the energy performance of the building with findings and additional building characteristics provide in a report by Deru et al. (2003).

\footnotetext{
${ }^{1}$ UFAD supply air temperatures are typically greater than $17^{\circ} \mathrm{C}\left(63^{\circ} \mathrm{F}\right)$. In conventional overhead air distribution systems, supply air temperatures are typically $13-16{ }^{\circ} \mathrm{C}\left(55-60{ }^{\circ} \mathrm{F}\right)$.

${ }^{2}$ The Leadership in Energy and Environmental Design credit system of the U.S. Green Building Council.
} 
For the present study, the characteristics of the HVAC systems in the study building are most relevant. The building has two mechanical rooms with associated HVAC equipment that serve the east and west wings of the building, respectively. Each mechanical room has a supply of outdoor air from a roofmounted air-to-air heat exchanger. The preheated or pre-cooled outdoor air from the heat exchangers is mixed with multiple airstreams ${ }^{3}$ of recirculated indoor air, thermally conditioned with ground-source heat pump units, and then supplied to the underfloor air supply plenums of the UFAD system. The conditioned air enters the occupied spaces of the building through air supply diffusers installed in the suspended floor. The supply diffusers are swirl diffusers that cause the exiting air to swirl about a vertical axis. Swirl diffusers are very common in UFAD systems because the swirl causes the supply air to rapidly mix with room air located near the floor, reducing the potential thermal discomfort from a cooled supply air jet. In addition, the swirl trajectory has less upward momentum than a simple plane jet. Excessive upward momentum could prevent the development of vertical thermal stratification and the attainment of a high value of air change effectiveness. Air exits the occupied spaces through return grilles located in the ceiling or walls. Return grilles were located 2.7 to $3.0 \mathrm{~m}$ (9.0 to $9.7 \mathrm{ft}$ ) above the floor. This return air is returned to the mechanical room where a portion, called the exhaust air, is directed to an airto-air heat exchanger that transfers heat between exhaust air and incoming outdoor air. The remainder of this return air is mixed with the preconditioned outdoor air and returned to the occupied spaces. Indoor temperature is maintained by cycling the operation of the ground source heat pumps that heat or cool the supply airstreams. The flow rates of outdoor and recirculated air are maintained constant. The building does not have an economizer control system to enable free cooling by increasing the supply of outdoor air when outdoor temperatures are mild.

\section{Overall measurement objectives}

The major measurement objectives were to determine the ventilation efficiency as indicated by the air change effectiveness and by the pollutant removal efficiency for carbon dioxide $\left(\mathrm{CO}_{2}\right)$, to quantify the extent of vertical thermal stratification, and to assess occupants' satisfaction with thermal conditions and indoor air quality. The methods used are described below.

\section{Air change effectiveness (ACE)}

The ACE a metric for ventilation efficiency and is a determined from measured values of age of air, where the age of a parcel of air represents the average time elapsed since the molecules in that parcel entered the building. In general, air that has been in the building for a longer time is likely to contain more indoor-generated air pollutants. While there is no rigorous definition of a local ventilation rate, the reciprocal of an age of air measured at a location can be informally considered as a local ventilation rate. Typically, age of air is expressed with units of hours, and its reciprocal then has units of $\mathrm{hr}^{-1}$, as does an air exchange rate.

The only known methods for measuring ACE are based on the use of tracer gases. We used the tracer gas stepup procedure with a measurement protocol similar to that defined in the ASHRAE measurement standard for ACE (ASHRAE 2002). To initiate the tracer stepup measurements, we started sulfur hexafluoride $\left(\mathrm{SF}_{6}\right)$ tracer gas injection into the two streams of incoming outdoor air. The injection rates were maintained constant at rates ${ }^{4}$ that produced the same $\mathrm{SF}_{6}$ concentration, within $5 \%$, in each stream of outdoor air. $\mathrm{SF}_{6}$ gas concentrations were measured versus time in exhaust airstreams, at return grilles, and at a representative set of breathing-level locations in the occupied space. After a few hours elapsed, indoor $\mathrm{SF}_{6}$ concentrations stabilized and the injection process and measurements were terminated. At each measurement location, the age of air was calculated using the equation

\footnotetext{
${ }^{3}$ Five airstreams and five associated ground source heat pumps serve the east wing of the building. Six airstreams and six associated ground source heat pumps serve the west wing of the building.

${ }^{4}$ The tracer gas injection rates in the two outdoor airstreams differed because the airstream flow rates differed.
} 


$$
A_{i}=\int_{0}^{\infty}\left(1-\frac{C_{i}(t)}{C_{\infty}(t)}\right) d t
$$

where $A_{i}$ is the age of air at location $i, C$ is the tracer gas concentration, $t$ is the time elapsed since the start of tracer gas injection, and $C_{\infty}$ is the steady state tracer gas concentration. In practice, the integral was evaluated numerically for the time period when tracer gas concentrations increased, which was approximately four hours. The ACE was calculated from the equation

$$
\mathrm{ACE}=\tau_{\mathrm{n}} / \mathrm{A}_{\mathrm{avg}}
$$

where $\tau_{\mathrm{n}}$ is the nominal time constant and $A_{\text {avg }}$ is the average age of air measured at the breathing level locations. The nominal time constant is the average age of air in airstreams exhausted from the building and equals the age of air that would occur throughout the building if the indoor air were perfectly mixed.

Because we were most interested in the ACE in the regions of the building where people spend most time, we also calculated local values of ACE, substituting the age of air at a return air grille for $\tau_{\mathrm{n}}$, and replacing $A_{\text {avg }}$ with the age of air at a nearby the seated or standing breathing-level measurement location.

If the air in rooms was well mixed, as it is in many buildings, the ACE would equal unity. Ideally, with UFAD the age of air where people breathe will be less than the age in the exhaust airstreams, i.e., the ACE will be greater than unity. In other words, in an effective ventilation process with ACE greater than unity the older air is exhausted to outdoors and the people inhale younger air that is likely to be less polluted air. True displacement ventilation systems often have an ACE of 1.2 to 1.4 (Skistad 2002) and our desk mounted task ventilation systems have produced ACE values greater than 1.5 in some operating conditions (Faulkner et. al 2003).

Tracer gas injection rates were maintained constant using speed-controlled peristaltic pumps that drew from a large gas storage bag. The readings of rotometers in the injection path were manually recorded to confirm stable injection rates. The $\mathrm{SF}_{6}$ was injected upstream of the outdoor air supply fans associated with the air-to-air heat exchanger, thus, the passage of injected tracer through the fans aided mixing of $\mathrm{SF}_{6}$ within the outdoor airstreams.

We measured tracer gas concentrations as a function of time at four sites per test in the occupied spaces, in each exhaust airstream, and in each stream of incoming outdoor air. Some measurement sites changed between tests. In the occupied spaces, two measurement sites were private offices and four measurement sites were at cubicles located in a larger open-plan office area that contained 12 to 22 workstations. At measurement sites in the occupied spaces, we monitored tracer gas concentrations versus time at two heights above the floor, representing the breathing level of seated and standing adults, and also at the nearest return air grille.

$\mathrm{SF}_{6}$ concentrations were measured using six gas analyzers that employ the photo-acoustic or nondispersive infrared methods. Multi-point sampling systems were used to collect data at up to three locations per gas analyzer. The analyzers were calibrated before and after the tests with multiple calibration gas standards.

To accurately measure ACE, the tracer gas concentration at each measurement location must be measured at least five times per nominal time constant (ASHRAE 2002). We measured concentrations at each location every three minutes, or at least 20 times per nominal time constant. Our prior laboratory based research indicates that the uncertainty in our measured values of ACE was approximately \pm 0.02 (Fisk et al. 1997). In field studies we anticipate a higher level of uncertainty. The ASHRAE Standard on measuring ACE (ASHRAE 2002) estimates that the maximum uncertainty in field-based measurements of ACE performed in accordance with the standard is \pm 0.16 . 


\section{Pollutant removal efficiency for carbon dioxide}

The ACE indicates the efficiency of the ventilation process in controlling exposures to an indoorgenerated pollutant emitted without momentum or buoyancy at locations spatially distributed within a building. The local pollutant removal efficiency (PRE) is a related parameter, but it indicates the efficiency of the ventilation process in controlling exposures to a real indoor pollutant which may have highly localized sources and be emitted with momentum, e.g., from a warm source. Thus, values of PRE can differ from values of ACE. Unfortunately, for most real pollutants measurements of PRE are impractical because of high measurement costs. However, it is practical to measure the PRE for $\mathrm{CO}_{2}$, which should be representative of the PRE for other occupant-generated pollutants. The local PRE for $\mathrm{CO}_{2}$ was calculated from the equation

$$
P R E_{\text {co } 2}=\Delta \overline{C_{R G}} / \Delta \overline{C_{b z}}
$$

where $\Delta \bar{C}$ equals the time-average difference between an indoor and outdoor work-day concentration of $\mathrm{CO}_{2}$, subscript "RG" refers to an indoor measurement at the return grille located nearest to the indoor measurement location, and subscript "bz" refers to an indoor measurement at a breathing zone height. We made separate $\mathrm{CO}_{2}$ measurements at the breathing height of seated and standing adults, 1.1 and $1.7 \mathrm{~m}$ (3.6 and $5.6 \mathrm{ft}$ ), respectively. Therefore, for each measurement site we calculated two corresponding values of local PRE, one based on $\mathrm{CO}_{2}$ measurements at seated breathing height and one based on $\mathrm{CO}_{2}$ measurements at standing breathing height - both calculations also used $\mathrm{CO}_{2}$ data from the nearest return grille. The reported values of PRE are 9 to 12-hour averages from the periods of occupancy of the office.

$\mathrm{CO}_{2}$ concentrations were measured and logged outdoors and at the same measurement sites where tracer gas concentrations were measured. Measurements were made using calibrated infrared $\mathrm{CO}_{2}$ analyzers. The $\mathrm{CO}_{2}$ analyzers were calibrated at ten concentrations with gas standards. The calibration curve derived from the calibration data fit individual calibration data points within $\pm 3 \%$. Each analyzer had a multiplexing sample system, with concentration data obtained one minute out of every three at each measurement location.

The errors in our reported values of PRE were greatly reduced by using the same instrument to measure $\mathrm{CO}_{2}$ at the return grill and breathing zone locations, the same instrument to measure all outdoor $\mathrm{CO}_{2}$ concentrations, and by averaging approximately 200 values of PRE measured at the same location each workday. Errors due to instrument bias were essentially eliminated, leaving errors due to measurement noise, which were reduced by averaging 200 measurements. The maximum level of short-term measurement noise in an individual measurement of $\mathrm{CO}_{2}$ concentration was approximately $\pm 14 \mathrm{ppm}$, which equals $14 \%$ of a typical-to-low 100 ppm difference between indoor and outdoor $\mathrm{CO}_{2}$ concentration. From propagation of error analyses, the associated uncertainty in a single measurement of PRE was $\pm 20 \%$ and the estimated uncertainty in the average 200 values of PRE was $1.4 \%$.

\section{Thermal stratification and associated energy savings factors}

To quantify the extent of thermal stratification in the occupied spaces, air temperatures were measured and logged at seven heights above the floor near the six sites of tracer gas and $\mathrm{CO}_{2}$ monitoring ${ }^{5}$. The measurement heights were 0.1, 0.6, 1.1, 1.7, 2.0, 2.2, and $2.5 \mathrm{~m}(0.3,2.0,3.6,5.6,6.6,7.2,8.2 \mathrm{ft})$ above the floor. We also measured temperatures at ten locations in the supply air plenums beneath the suspended floors at approximately one-half of the plenum height. The measurement locations in the supply air plenums included sites located within 0.1 to $0.2 \mathrm{~m}$ ( 1 to $2 \mathrm{ft}$ ) of each vertical array of indoor air temperature sensors. The sensors have a resolution of $0.2{ }^{\circ} \mathrm{C}\left(0.1^{\circ} \mathrm{F}\right)$. Their performance was compared relative to a NIST traceable sensor. The outputs of all sensors were inter-compared immediately after the

\footnotetext{
${ }^{5}$ Sensors were located away from windows to reduce the impacts of solar radiation on the measured temperatures.
} 
field study. Because we were interested in the extent of stratification, small differences in sensor calibration were important, therefore, we applied a correction factor to each sensor. The correction factor, based on data from the sensor intercomparison, was the difference between the sensor reading (averaged over 30 minutes) at $22{ }^{\circ} \mathrm{C},\left(72{ }^{\circ} \mathrm{F}\right)$ and the average reading of all 65 sensors at $22{ }^{\circ} \mathrm{C}\left(72{ }^{\circ} \mathrm{F}\right)$. After applying the correction factor, at normal room temperatures the readings of all sensors were within a $\pm 0.05{ }^{\circ} \mathrm{C}\left( \pm 0.1{ }^{\circ} \mathrm{F}\right)$ band; thus, the uncertainty in a calculated temperature difference is approximately $\pm 0.1{ }^{\circ} \mathrm{C}\left( \pm 0.2^{\circ} \mathrm{F}\right)$, partly due to bias and partly due to signal noise.

As detailed in appendix 1, vertical thermal stratification can reduce the energy consumed by air conditioning systems for sensible space cooling. The amount of energy needed to cool recirculated indoor air is unaffected by thermal stratification. However, the amount of energy needed for sensible cooling of incoming outdoor air can be reduced when there is temperature stratification in the building because the stratification enables a small increase in supply air temperature and corresponding increase in return air temperature. The amount of energy savings is proportional to the difference between the air temperature in the occupied zone $T_{O Z}$ and the air temperature of the return air $T_{R}$.

$$
\Delta T=T_{R}-T_{o z}
$$

For our analyses of study data, the value of $\mathrm{T}_{\mathrm{oz}}$ was based on the average of all temperature data collected between the heights of 0.1 and $1.7 \mathrm{~m}(0.3$ and $5.6 \mathrm{ft})$. We calculated time-average values of $\Delta \mathrm{T}$.

In appendix 1, we derive two energy savings fraction terms that quantify the potential energy savings from thermal stratification. The first savings fraction term $\left(\mathrm{SF}_{\mathrm{OA}}\right)$ represents the reduction in sensible heat removal required of the air conditioner with thermal stratification divided by the sensible heat removal necessary to cool incoming outdoor air to the return air temperature. This metric is particularly relevant because it is the cooling loads for incoming outdoor air that are diminished by thermal stratification. The corresponding equation is

$$
S F_{O A}=\frac{M X \Delta T}{M X\left(T_{O A}-T_{R}\right)}
$$

where $\mathrm{M}$ equals the product of mass flow rate and specific heat of air flowing through the cooling coil; $\mathrm{X}$ is the fraction of outdoor air in the supply airstream, and $\mathrm{T}_{\mathrm{OA}}$ is the outdoor air temperature. The second savings fraction $\left(\mathrm{SF}_{\text {TOTAL }}\right.$ ) has the same numerator, but the reference (i.e., denominator) is the total sensible heat removal by the air conditioning unit.

$$
S F_{T O T A L}=\frac{M X(\Delta T)}{M X\left(T_{O A}-T_{C C}\right)+M(1-X)\left(T_{R}-T_{O A}\right)}
$$

where $\mathrm{T}_{\mathrm{CC}}$ is the temperature of air exiting the cooling coil.

\section{Supplementary calculations and information collection}

Supplementary measurements and calculations were performed to characterize building and HVAC operating conditions that may influence ACE, PRE, and the extent of thermal stratification. The outdoor air flow rates were calculated from the $\mathrm{SF}_{6}$ injection rates and resulting concentrations of $\mathrm{SF}_{6}$ in the outdoor airstreams. Supply air flow rates per unit floor area were based on documentation provided by the facility manager ${ }^{6}$. To estimate the internal heat generation rate, we started with estimated lighting and plug loads from measurements by (Deru et al. 2003). They estimated that overhead and task lighting in

\footnotetext{
${ }^{6}$ Supply flow rates per unit floor area were based on supply flow rates or each heat pump unit from equipment schedules on drawings and the floor area served by each heat pump unit.
} 
the office areas consumed approximately $11 \mathrm{~W} / \mathrm{m}^{2}\left(1 \mathrm{~W} / \mathrm{ft}^{2}\right)$ and that plug loads ${ }^{7}$ were approximately 6 $\mathrm{W} / \mathrm{m}^{2}\left(0.5 \mathrm{~W} / \mathrm{ft}^{2}\right)$. We added an estimate of internal heat generation of occupants, based on a counting of occupants in each study area once per day (between 10:30 and 13:45) and an assumed sensible heat release per occupant of $75 \mathrm{~W}$.

\section{Occupant Survey}

All occupants were asked to complete a survey that is accessed via the Internet. The survey (Huizenga et al. 2003) collects background information on the respondents and their workspaces and asked the occupants to rate their level of satisfaction with office layout, furnishings, thermal comfort, air quality, lighting, acoustic quality, and cleanliness. In responses to core questions, the respondents indicate their level of satisfaction with a building condition on a seven-point scale, ranging from +3 representing very satisfied to -3 representing very dissatisfied, with a rating of zero indicating a neutral response ${ }^{8}$. Figure 1 shows an example of a question. The users selected one of the circles on the scale. In addition, a special section of the survey asked about use of and satisfaction with the UFAD system. The responses from occupants in this study building were compared to average responses obtained from use of the survey in 67 buildings $^{9}$ - four with UFAD. Seventy eight percent of these buildings were located in the U.S., 79\% were government owned, $70 \%$ were offices, and $24 \%$ were courthouses. Approximately 10 minutes was needed to complete the survey. The confidentiality of respondents was maintained. The survey process was approved by the Committee for Protection of Human Subjects at the University of California, Berkeley.

\section{How satisfied are you with the temperature in your workspace? very Satisfied a 0000000 very Dissatisfied}

Figure 1. Example survey question

\section{RESULTS}

\section{Study Sites and Environmental and Operating Conditions During Study}

Measurements were performed on four days in April of 2004. Table 1 characterizes the six study sites in the occupied regions of the building. On study days, the maximum outdoor air temperature ranged from 3 to $12{ }^{\circ} \mathrm{C}$ (38 to $53{ }^{\circ} \mathrm{F}$ ) and the minimum outdoor temperature ranged from -1 to $2{ }^{\circ} \mathrm{C}$ (31 to $36{ }^{\circ} \mathrm{F}$ ).

Between 7:00 and 11:00, supply air temperatures were sometimes higher than occupied space temperatures, indicating that spaces within the building were being heated. Measured two-hour average supply air temperatures during periods of space heating ranged from approximately 22.4 to $25.8{ }^{\circ} \mathrm{C}(72.3$ to $78.4^{\circ} \mathrm{F}$ ). After 11:00 and at some locations before 11:00, supply air temperatures averaged over twohour periods were lower than the occupied space temperatures, indicating that occupied spaces were being cooled. During cooling, two-hour average supply air temperatures were between approximately 21.7 and $23.9{ }^{\circ} \mathrm{C}\left(71.1\right.$ and $\left.75.0{ }^{\circ} \mathrm{F}\right)$.

\footnotetext{
${ }^{7} 18 \mathrm{KW}$ during occupied hours divided by total building floor area.

${ }^{8}$ The numbers associated with the seven-point scale are used for the analysis only. The semantic differential scales on the computerized form completed by respondents are labeled only with text at the end points.

${ }^{9}$ Includes the present study building
} 
Table 1. Characteristics of the study sites.

\begin{tabular}{|c|c|c|c|c|c|c|c|c|c|}
\hline $\begin{array}{c}\text { Site } \\
\text { Code } \\
\#\end{array}$ & Floor & $\begin{array}{c}\text { Space } \\
\text { Type* } \\
\text { Area } \\
\left(\mathbf{m}^{2}, \mathbf{f t}^{2}\right)\end{array}$ & $\begin{array}{l}\text { No. of } \\
\text { Work- } \\
\text { stations }\end{array}$ & $4 / 12$ & $\begin{array}{l}\text { Numb } \\
\text { Occup } \\
4 / 13\end{array}$ & $\begin{array}{l}\text { er of } \\
\text { ants } \\
4 / 14\end{array}$ & $4 / 15$ & $\begin{array}{c}\text { Design Supply Flow in } \\
\text { Site } \\
\mathrm{L} / \mathrm{s}-\mathrm{m}^{2} \\
\left(\mathrm{cfm} / \mathbf{f t}^{2}\right)\end{array}$ & $\begin{array}{c}\text { Estimated internal } \\
\text { Heat Generation } \\
\mathrm{W} / \mathbf{m}^{2}\left(\mathrm{~W} / \mathbf{f t}^{2}\right)\end{array}$ \\
\hline 1 & 1 & $\begin{array}{c}\text { CS } \\
(275,2960)\end{array}$ & 22 & 10 & 6 & ---- & ---- & $\begin{array}{c}0.018-0.031 \\
(0.4 \text { to } 0.7)\end{array}$ & \multirow{6}{*}{$16-20(1.5-1.9)$} \\
\hline 2 & 2 & $\begin{array}{c}\mathrm{PO} \\
(18.5,200)\end{array}$ & 1 & $\begin{array}{l}--- \\
--\end{array}$ & $\begin{array}{ll}--- \\
\end{array}$ & 0 & 1 & $\begin{array}{c}0.035 \\
(0.8)\end{array}$ & \\
\hline 3 & 2 & $\begin{array}{c}\text { CS } \\
(277,2990)\end{array}$ & 15 & 12 & 13 & 7 & 9 & $\begin{array}{l}0.026 \\
(0.6)\end{array}$ & \\
\hline 4 & 2 & $\begin{array}{c}\text { CS } \\
(277,2990)\end{array}$ & 14 & 11 & 11 & ---- & ---- & $\begin{array}{l}0.026 \\
(0.6)\end{array}$ & \\
\hline 5 & 2 & $\begin{array}{c}\mathrm{PO} \\
(17.6,190)\end{array}$ & 1 & ---- & ---- & 0 & 0 & $\begin{array}{c}0.026 \\
(0.6)\end{array}$ & \\
\hline 6 & 2 & $\begin{array}{c}\text { CS } \\
(162,1740)\end{array}$ & 12 & 10 & 8 & 9 & 6 & $\begin{array}{l}0.035 \\
(0.8)\end{array}$ & \\
\hline
\end{tabular}

* CS $=$ room with cubicles enclosing workstations $\mathrm{PO}=$ private office

$\wedge$ The number of occupants present when occupants were counted by a researcher between 10:30 and 13:45.

\section{Air Change Effectiveness (ACE)}

The measured values of ACE based on the average exhaust airstream age of air and the average of ages of air at the seated breathing level ranged from 0.90 to 1.03 and averaged 0.98 . When instead we used the average ages of air at the breathing height of standing adults, the ACE ranged from 0.89 to 1.01 and averaged 0.96. The 16 measured values of local ACE based on ages of air at return grilles and at the breathing height of seated workers ranged from 0.98 to 1.15 and averaged 1.04. The 16 measured values of local ACE based on ages of air at return grilles and at the breathing height of standing workers ranged from 0.98 to 1.10 and averaged 1.02. These ACE and local ACE values are not significantly different from unity given our estimated measurement uncertainty. Thus, the ACE in this building was indistinguishable from the ACE that would occur in a building with perfectly mixed indoor air.

\section{Pollutant removal efficiency}

Figure 1 illustrates the results of the PRE measurements. The 16 values of local PRE based on $\mathrm{CO}_{2}$ measurements at the seated breathing level height $(1.1 \mathrm{~m}, 3.6 \mathrm{ft})$ and at the nearby return grille ranged from 1.03 to 1.32 and averaged 1.13. Considering our estimated measurement uncertainty of $1.4 \%$ for workday average values of PRE, the data indicate that the PRE for $\mathrm{CO}_{2}$ at the seated breathing height is significantly higher than in a space with well-mixed air, which would have a PRE of 1.0. The 16 measurements of local PRE based on measurements at the standing breathing level height $(1.7 \mathrm{~m}, 5.6 \mathrm{ft})$ ranged from 0.92 to 1.24 and averaged 1.05 . The elevation above unity of 0.05 only slightly exceeds our uncertainty estimate. Because most workers are seated, the PRE value of 1.13 is most relevant. One can estimate that concentrations of other occupant-generated pollutants at the inhalation zone are reduced by approximately $13 \%$ relative to an air distribution system that supplies the same amount of outdoor air and results in thorough mixing in rooms. 

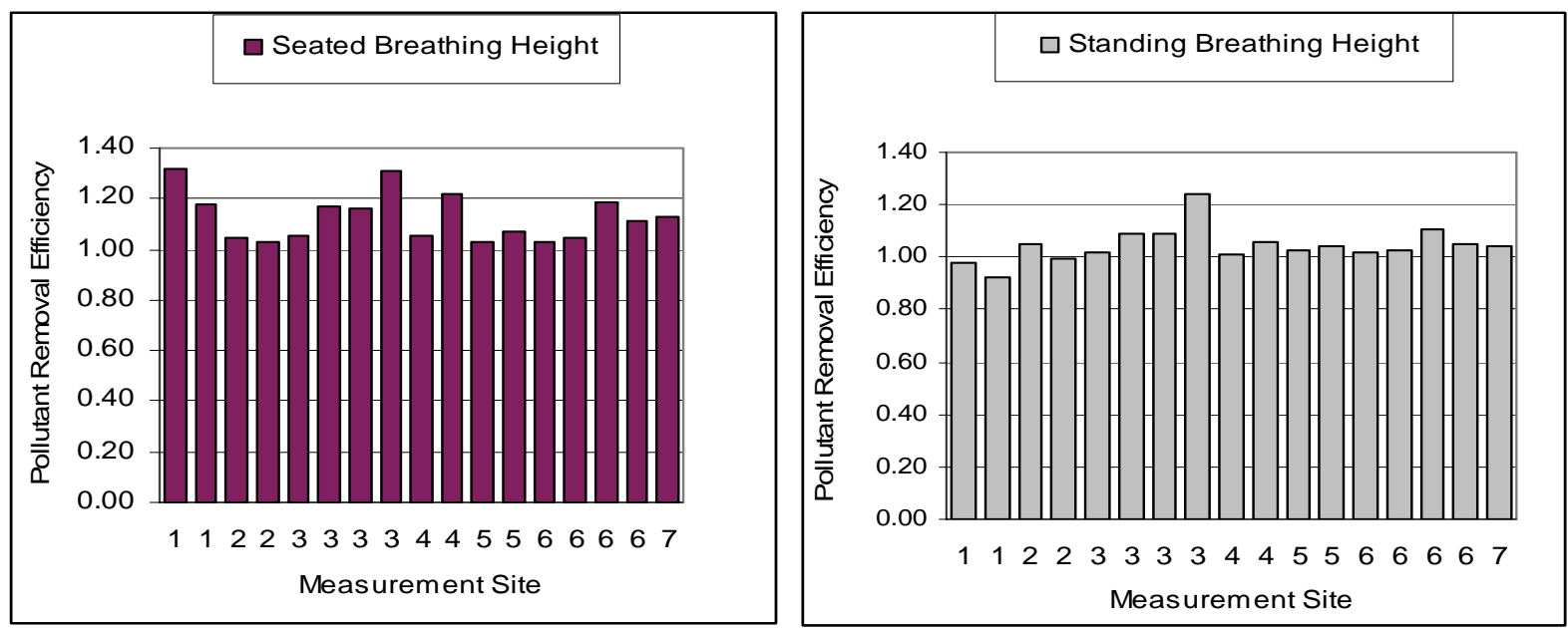

Figure 1. Measured values of pollutant removal efficiency (PRE) for carbon dioxide. With perfect mixing, the PRE would equal unity.

\section{Thermal stratification}

Figure 2a provides a typical example of the profile of air temperature with height, based on average temperatures for two-hour periods at measurement site 4 . In this figure, the temperatures at a height of $0 \mathrm{~m}$ represent the temperatures of the supply air. At this measurement site, between 7 and 9 am the space was being heated, thereafter it was being cooled. Temperatures increased $1{ }^{\circ} \mathrm{C}\left(2{ }^{\circ} \mathrm{F}\right)$ or less between heights of 0.1 and $3 \mathrm{~m}(0.3$ and $9.8 \mathrm{ft})$. Figure $2 \mathrm{~b}$ provides an example of the air temperature profile at the first floor cubicle location (measurement site 1 ) where temperatures increased by the largest amount with height. At this location, the air temperature increased approximately $2{ }^{\circ} \mathrm{C}\left(4{ }^{\circ} \mathrm{F}\right)$ between heights of 0.1 and $3 \mathrm{~m}$ ( 0.3 and $9.8 \mathrm{ft})$. Based on the information in Table 1 , site 4 and site 1 had similar estimated thermal loads and supply flow rates. The ceiling height at site 1 ranged from $2.9 \mathrm{~m}(9.7 \mathrm{ft})$ at the building perimeter to a maximum of $6.1 \mathrm{~m}(20 \mathrm{ft})$, while the ceiling height in site 4 was a fixed $2.9 \mathrm{~m}(9.7 \mathrm{ft})$.
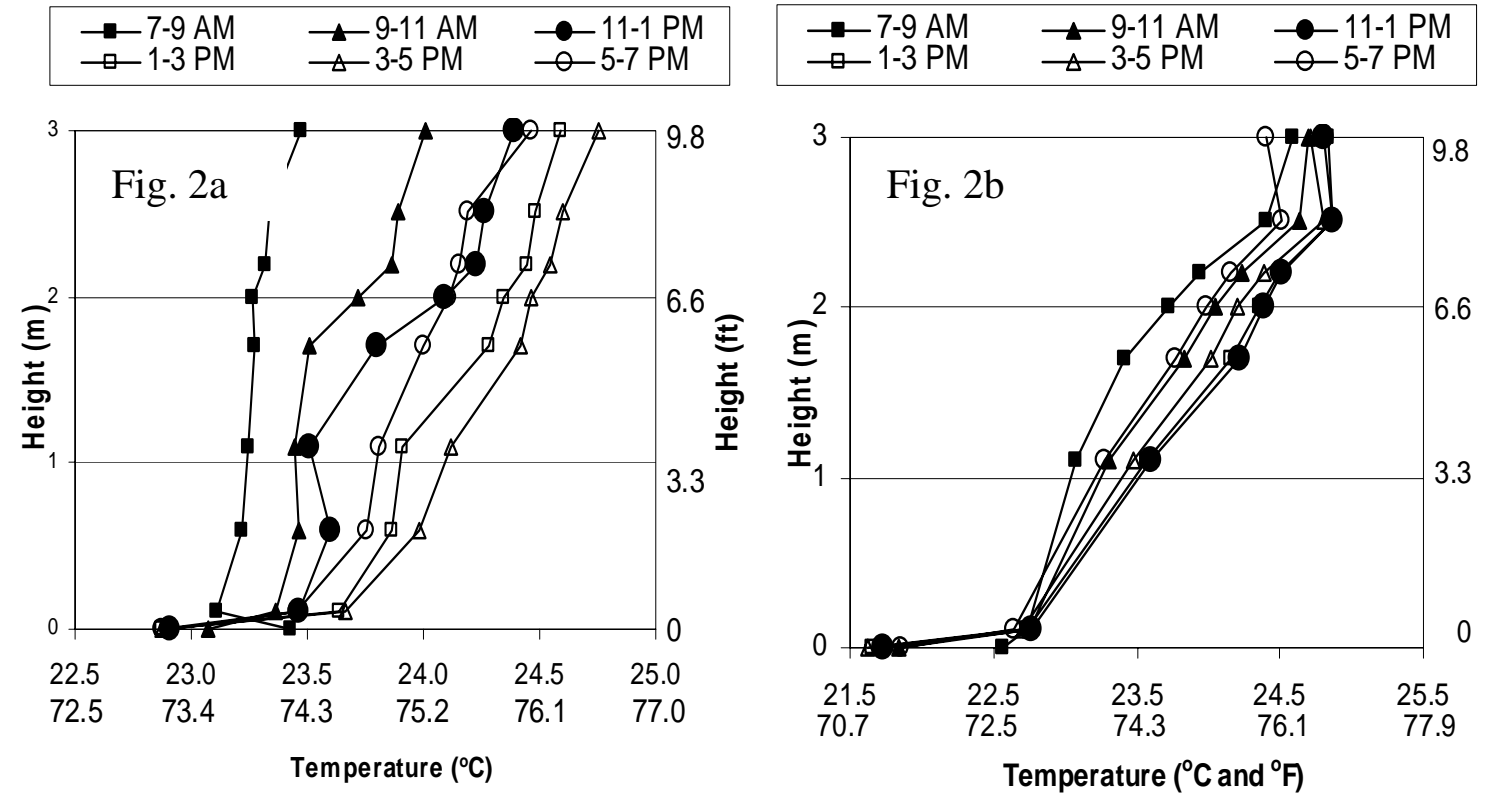

Figure 2. Examples of vertical temperature profiles. Figure 2a is from measurements at site 4 and Figure $2 \mathrm{~b}$ is based on measurements at site 1 . 
Table 2 indicates the degree of indoor temperature stratification and the heat removal effectiveness at each measurement site during periods of space cooling (after 11:00). The numbers in the table are time averages for all days of measurements. In absolute terms, the extent of temperature stratification was small, i.e., the air temperature at the return grille was less than $1{ }^{\circ} \mathrm{C}\left(2{ }^{\circ} \mathrm{F}\right)$ higher than the temperature just above the floor at a height of $0.1 \mathrm{~m}$. However, during these measurements the temperature difference between the supply air and nearby return air grille averaged only 0.7 to $2 .{ }^{\circ} \mathrm{C}\left(1.2\right.$ to $\left.5.2{ }^{\circ} \mathrm{F}\right)$; thus, it was not possible to have a large temperature stratification in the occupied space. The difference between return air temperature and average temperature in the occupied zone (see Equation 4) ranged from 0.5 to $1.2{ }^{\circ} \mathrm{C}\left(0.9\right.$ to $\left.2.2{ }^{\circ} \mathrm{F}\right)$ and averaged $0.7^{\circ} \mathrm{C}\left(1.3^{\circ} \mathrm{F}\right)$.

Table 2. Vertical temperature stratification during periods of cooling (11:00 - 19:00)

\begin{tabular}{|c|c|c|c|c|c|c|}
\hline $\begin{array}{c}\text { Site } \\
\text { Code } \\
\#\end{array}$ & $\begin{array}{l}\text { Space } \\
\text { Type* }\end{array}$ & $\begin{array}{c}\text { Temp at Return } \\
\text { Grille } \\
\text { minus } \\
\text { Temp Supply } \\
\text { Air } \\
{ }^{\circ} \mathrm{C}\left({ }^{\circ} \mathrm{F}\right) \\
\end{array}$ & $\begin{array}{c}\text { Temp at } \\
\text { Return Grille } \\
\text { minus } \\
\text { Temp at } 0.1 \mathrm{~m} \\
{ }^{\mathbf{0}} \mathrm{C}\left({ }^{0} \mathrm{~F}\right)\end{array}$ & $\begin{array}{l}\text { Temp at } 1.7 \mathrm{~m} \\
\text { minus } \\
\text { Temp at } 0.1 \mathrm{~m} \\
{ }^{\circ} \mathrm{C}\left({ }^{\circ} \mathrm{F}\right)\end{array}$ & $\begin{array}{l}\text { Temp at } 1.1 \mathrm{~m} \\
\text { minus } \\
\text { Temp at } 0.1 \mathrm{~m} \\
{ }^{\circ} \mathrm{C}\left({ }^{\circ} \mathrm{F}\right)\end{array}$ & $\begin{array}{c}\text { Temp at Return } \\
\text { Grille divided by } \\
\text { average Temp in } \\
\text { occupied zone } \\
{ }^{\circ} \mathrm{C}\left({ }^{\circ} \mathrm{F}\right)\end{array}$ \\
\hline 1 & CS & $2.9(5.2)$ & $1.9(3.4)$ & $1.3(2.4)$ & $0.7(1.3)$ & $1.2(2.2)$ \\
\hline 2 & $\mathrm{PO}$ & 0.7 (1.3) & $0.7(1.2)$ & $0.3(0.5)$ & $0.2(0.3)$ & $0.5(1.0)$ \\
\hline 3 & CS & $1.6(2.8)$ & $0.9(1.5)$ & $0.4(0.7)$ & $0.2(0.4)$ & $0.7(1.2)$ \\
\hline 4 & $\mathrm{CS}$ & $1.7(3.1)$ & $1.1(2.0)$ & $0.7(1.2)$ & $0.4(0.7)$ & $0.7(1.3)$ \\
\hline 5 & $\mathrm{PO}$ & $0.7(1.2)$ & $0.7(1.3)$ & $0.3(0.6)$ & $0.3(0.5)$ & $0.5(0.9)$ \\
\hline 6 & CS & 0.9 (1.6) & 0.7 (1.3) & $0.4(0.8)$ & $0.3(0.5)$ & $0.5(0.9)$ \\
\hline
\end{tabular}

\section{Rates of Outdoor Air Supply and Peak $\mathrm{CO}_{2}$ Concentrations}

Table 3 provides the measured rates of outdoor air supply for the east and west wings of the building, served by the east and west air HVAC systems, respectively. The rate of outdoor air supply per unit floor area was approximately $0.7 \mathrm{~L} / \mathrm{s}-\mathrm{m}^{2}\left(0.14 \mathrm{cfm} / \mathrm{ft}^{2}\right)$ in the east wing of the building and approximately 1.2 $\mathrm{L} / \mathrm{s}-\mathrm{m}^{2}\left(0.23 \mathrm{cfm} / \mathrm{ft}^{2}\right)$ in the west wing of the building. The west wing had approximately twice as many occupants as the east wing. The rate of outdoor air supply per workstation, which would equal the rate of outdoor air supply per occupant with full occupancy, was approximately $30 \mathrm{~L} / \mathrm{s}$ (60 cfm). The largest measured difference between an indoor 1-hour average and outdoor $\mathrm{CO}_{2}$ concentration was $280 \mathrm{ppm}$, which is substantially less than the informal guideline maximum of $650 \mathrm{ppm}$.

The amount of air infiltration in the study building can be estimated from the ratio of steady state indoor tracer gas concentration to concentration of tracer gas in the incoming outdoor air (Fisk et al. 1988). In the study building, this ratio was approximately 0.8 ; thus, $80 \%$ of the air in the building entered through the HVAC systems and $20 \%$ entered by air infiltration. 
Table 3. Rates of outdoor air supply and peak $\mathrm{CO}_{2}$ concentrations.

\begin{tabular}{|c|c|c|c|c|}
\hline & \multicolumn{4}{|c|}{ Date } \\
\hline Outdoor Air Supply in East HVAC & $4 / 12$ & $4 / 13$ & $4 / 14$ & $4 / 15$ \\
\hline $\mathrm{L} / \mathrm{s}(\mathrm{cfm})$ & $1,000(2100)$ & $940(2000)$ & $960(2000)$ & $910(1900)$ \\
\hline $\mathrm{L} / \mathrm{s}-\mathrm{m}^{2}\left(\mathrm{cfm} / \mathrm{ft}^{2}\right)$ & $0.72(0.14)$ & $0.68(0.13)$ & $0.69(0.14)$ & $0.65(0.13)$ \\
\hline L/s-workstation (cfm/workstation) & $30(65)$ & $28(61)$ & $29(62)$ & $28(58)$ \\
\hline \multicolumn{5}{|l|}{ Outdoor Air Supply in West HVAC } \\
\hline $\mathrm{L} / \mathrm{s}(\mathrm{cfm})$ & $2,000(4300)$ & $1,900(4100)$ & $2,000(4100)$ & $1,900(3900)$ \\
\hline $\mathrm{L} / \mathrm{s}-\mathrm{m}^{2}\left(\mathrm{cfm} / \mathrm{ft}^{2}\right)$ & $1.21(0.24)$ & $1.15(0.23)$ & $1.21(0.23)$ & $1.15(0.22)$ \\
\hline L/s-workstation (cfm/workstation) & $29(62)$ & $27(58)$ & $29(59)$ & $27(56)$ \\
\hline \multicolumn{5}{|l|}{$\begin{array}{l}\text { Peak } 1 \text { hr Average Return Air } \\
\text { Minus Outdoor Air } \mathrm{CO}_{2}\end{array}$} \\
\hline Site $1(\mathrm{ppm})$ & 160 & 220 & --- & --- \\
\hline Site 2 (ppm) & $\begin{array}{ll}-- \\
\end{array}$ & $\begin{array}{l}--- \\
\end{array}$ & 230 & 250 \\
\hline Site 3 (ppm) & 260 & 270 & 200 & 160 \\
\hline Site 4 (ppm) & 230 & 180 & $\begin{array}{ll}-- \\
-\end{array}$ & $\begin{array}{ll}-- \\
\end{array}$ \\
\hline Site 5 (ppm) & --- & --- & 170 & 150 \\
\hline Site $6(\mathrm{ppm})$ & 280 & 270 & 230 & 210 \\
\hline
\end{tabular}

\section{Survey Results}

The survey was made available to 95 workers and 45 (47\%) completed the survey. The response rate may have been diminished because many employees spent much of their work time away from the building. However it is near the $50 \%$ threshold considered appropriate for census surveys such as this one to reduce non-response bias to an acceptable rate (Hill et al. 1999). Seven percent of survey respondents were less than 30 years old, $62 \%$ had an age of 31 to 50, and 31\% were older than 50 . Sixty nine percent of survey respondents were male, $76 \%$ worked in cubicles, and $51 \%$ worked more than 30 hours per week in their workspace.

Table 4 summarizes key results from the survey and provides data on building-mean survey responses from the reference population of 67 buildings. The respondents in the study building were most satisfied with office furnishings (comfort, adjustability, and color and texture), with thermal comfort, and with cleaning and maintenance. The level of satisfaction with lighting (amount and visual comfort) was particularly low, at the $8^{\text {th }}$ percentile, despite the attention to providing natural light in the building. The survey responses most likely to be affected by the UFAD system were thermal comfort and air quality. Thermal comfort ratings were substantially above average, at the $85^{\text {th }}$ percentile. Air quality ratings were slightly below average, at the $40^{\text {th }}$ percentile. However, many factors unrelated to the type of air distribution system may have influenced ratings of thermal comfort and air quality, for example air temperature setpoints and the strength of indoor air pollutant sources. As one specific example, we note that open-ended comments from the survey revealed that some occupants in the study building worked directly above a laboratory which at times emitted odors. Fifty seven percent of respondents indicated that they preferred the UFAD system to conventional overhead air distribution systems. 
Table 4. Key results of survey.

\begin{tabular}{|c|c|c|c|}
\hline \multirow{2}{*}{ Survey Questions } & \multirow{2}{*}{$\begin{array}{c}\text { Reference } \\
\text { Buildings } \\
\text { Mean } \\
\text { Response } \\
\end{array}$} & \multicolumn{2}{|c|}{ Study Building } \\
\hline & & $\begin{array}{c}\text { Mean } \\
\text { Response }\end{array}$ & $\begin{array}{c}\text { Percentile } \\
\text { Rank }\end{array}$ \\
\hline $\begin{array}{l}\text { Satisfaction with:* } \\
\text { Office layout (space, visual privacy, ease of interactions)+ } \\
\text { Office furnishings (comfort, adjustability, color and } \\
\text { texture)+ } \\
\text { Thermal comfort } \\
\text { Air quality } \\
\text { Lighting (amount, visual comfort)+ } \\
\text { Acoustics (noise level, sound privacy)+ } \\
\text { Cleaning and maintenance (cleanliness, cleaning service, } \\
\text { general maintenance)+ } \\
\text { Overall workplace satisfaction } \\
\text { Overall building satisfaction }\end{array}$ & $\begin{array}{c}0.82 \\
0.79 \\
-0.17 \\
0.19 \\
0.96 \\
-0.26 \\
\\
0.64 \\
0.73 \\
0.78 \\
\end{array}$ & $\begin{array}{c}0.51 \\
1.36 \\
0.58 \\
-0.09 \\
0.00 \\
-0.74\end{array}$ & $\begin{array}{c}25 \\
\\
86 \\
85 \\
40 \\
8 \\
29 \\
\\
85 \\
30 \\
41 \\
\end{array}$ \\
\hline Prefer UFAD to conventional overhead air distribution & NA & $57 \%$ & NA \\
\hline
\end{tabular}

*Reported satisfaction on a seven-point scale, ranging from +3 representing very satisfied to -3 representing very dissatisfied, with a rating of zero indicating a neutral response.

+The reported satisfaction ratings are averages from responses to two or three questions pertaining to the dimensions in parentheses.

\section{DISCUSSION}

\section{UFAD ventilation performance}

In our studies of this building with an UFAD system, the measured values of air change effectiveness (ACE) were very close to unity. In the U.S., the ACE is also normally very close to unity with traditional overhead air distribution systems (Fisk et al. 1992, 1997; Olesen and Seelen 1992; Persily 1986; Persily and Dols 1989). Thus, this study identified no significant improvement in ACE with UFAD. However, to the best of our knowledge, this is the first field study of ACE in a building with UFAD. With different UFAD equipment or different operating conditions, such as less air recirculation, it is possible that UFAD systems result in higher values of ACE. We estimated ${ }^{10}$ that the fraction of outdoor air in the supply airstream was approximately 0.2 in the east HVAC system and 0.4 in the west HVAC system, thus 60 to $80 \%$ of the supply air was recirculated indoor air. These recirculation rates, which are typical for U.S. buildings, could have prevented high values of ACE. Unfortunately, in the study building it was not possible to increase the percentage of outdoor air in the supply airstream, i.e., reduce the recirculation, and assess the effect on ACE.

The $\mathrm{CO}_{2}$ measurements indicated that the pollutant removal efficiency for $\mathrm{CO}_{2}$ was about $13 \%$ higher than expected in a building with thoroughly mixed indoor air. We would expect similar values of pollutant removal efficiency for other occupant-generated pollutants. These results suggest that the UFAD process reduced exposures to occupant-generated pollutants by roughly $13 \%$. However, we have no reference PRE data from buildings with typical overhead air distribution systems; hence, it is possible, that slightly elevated values of pollutant removal efficiency also occur in typical buildings.

The field study data indicates that study building did have high rates of outdoor air supply per workstation, approximately three times the minimum rate specified per occupant in current ventilation

\footnotetext{
${ }^{10}$ Estimated by dividing our measured rates of outdoor air supply per unit floor area by the design values of supply air flow per unit floor area.
} 
standards (ASHRAE 2001). Our data also indicate that the number of occupants present was about $40 \%$ less than the number of workstations; thus, the rate of outdoor air supply per actual occupant present was more than three times the rate specified in ventilation standards. These high ventilation rates explain the low peak indoor $\mathrm{CO}_{2}$ concentrations. Despite the high rates of outdoor air supply, satisfaction with air quality was slightly below average $\left(40^{\text {th }}\right.$ percentile). We would not expect the rate of outdoor air supply to be a consistent predictor of satisfaction with air quality in individual buildings because other factors such as indoor pollutant generation rates also strongly affect air quality. However, from studies of large sets of buildings, on average, the satisfaction with air quality has improved with an increased outdoor air supply rate (Seppanen et al. 1999).

\section{Temperature stratification and implications for energy savings}

The measured increase in indoor temperature between locations just above the floor and the return air grilles was small, always less than $1.9^{\circ} \mathrm{C}\left(3.4^{\circ} \mathrm{F}\right)$. The combination of low internal thermal loads and moderate supply air flow rates in the study building were such that one could not expect a large amount of vertical thermal stratification. Therefore, it is possible that more thermal stratification would have occurred, as observed in controlled laboratory studies (Webster et al. 2002), if supply air flow rates were lower or internal heat generation rates were increased. For example, more thermal stratification would be expected if the building had full occupancy (more heat loads) or had a variable air volume ventilation system that automatically reduced supply flow rates when the demand for cooling was low.

Although the magnitude of temperature stratification was small, the results indicate a potential for energy savings during periods of air conditioning. To estimate the potential energy savings, we can apply equations 5 and 6 using examples of the temperatures and outdoor air fraction encountered during periods of air conditioning. For these example calculations, we assume $\mathrm{T}_{\mathrm{OA}}, \mathrm{T}_{\mathrm{R}}, \mathrm{T}_{\mathrm{CC}}$, and $\mathrm{X}$ equal $33{ }^{\circ} \mathrm{C}\left(91.4{ }^{\circ} \mathrm{F}\right)$, $25{ }^{\circ} \mathrm{C}\left(75.2{ }^{\circ} \mathrm{F}\right), 14{ }^{\circ} \mathrm{C}\left(57.2^{\circ} \mathrm{F}\right)$, and 0.3 , respectively. With these assumptions, each $1{ }^{\circ} \mathrm{C}\left(1.8^{\circ} \mathrm{F}\right)$ difference between $\mathrm{T}_{\mathrm{R}}$ and $\mathrm{T}_{\mathrm{OZ}}$ corresponds to a $11 \%$ reduction in the energy required for the sensible cooling of incoming outdoor air $\left(\mathrm{SF}_{\mathrm{OA}}\right)$ or a $3 \%$ reduction in the total energy used by the air conditioning system for sensible space cooling $\left(\mathrm{SF}_{\mathrm{TOTAL}}\right)$. If the air conditioning system dehumidifies the incoming outdoor air without decreasing Tcc below the temperature needed for sensible space cooling, the actual energy savings will be larger than indicated by these example calculations. However, if, for purposes of dehumidification, the incoming outdoor air is cooled below the temperature needed for sensible space cooling and then reheated, the stratification may lead to no energy savings. The other potential sources of energy savings from UFAD, such as the opportunity to increase the use of outdoor air for free cooling and the reduced fan energy consumption from reduced supply airstream pressure drops and air flow rates, ${ }^{11}$ were not evaluated in this study.

If a building is being heated with warmed supply air, thermal stratification will increase the heating energy use because it increases the temperature, hence the energy content, of air exhausted to outdoors by the HVAC system. However, from a consideration of basic fluid dynamics we would expect heating of a building with a UFAD system to cause less thermal stratification than heating of a building with a conventional air distribution system that supplies and removes warm air at the ceiling. Thus, UFAD systems may also reduce heating energy consumption; however, measurements of temperature gradients under conditions with heating are necessary before any conclusions are drawn.

We caution that the temperature stratification data from this study need to be confirmed in other studies performed in buildings with UFAD, both with similar and with other operating conditions. The present results were based on data from one building with very limited variability in operating conditions.

\footnotetext{
${ }^{11}$ We assumed that supply flow rates were maintained unchanged and supply air temperatures were increased with UFAD because this assumption seems to best match actual practice. However, another option is to decrease supply flow rates and maintain supply temperatures unchanged.
} 


\section{Survey results}

Based on the survey, the occupant's level of satisfaction with most characteristics of the building was comparable to mean level of satisfaction of occupants in reference buildings. The level of satisfaction with thermal comfort was at the $85^{\text {th }}$ percentile, and this high satisfaction rating could possibly be due, in all or part, to the use of a UFAD system. However, the percentile ranks of thermal comfort ratings from four UFAD buildings that have completed the survey have varied considerably (95\%, 36\% ${ }^{12}, 85 \%, 48 \%$ ), with a mean percentile rank of $66 \%$. Therefore, in this very small sample, the level of thermal comfort in UFAD buildings was only moderately superior to the average level of thermal comfort in conventional buildings. The low satisfaction rating for lighting, at the $8^{\text {th }}$ percentile, was the most striking finding from the survey; however, the presence or absence of UFAD does not likely affect satisfaction with lighting. The occupants who were dissatisfied with lighting reported that it was too dark (82\%), that there was not enough daylight (59\%), and that there was not enough electric lighting (68\%). While the web-based survey was easy to use and very informative, the current reference database was modest in size. Ideally, one would compare the survey responses from this study building to responses from a large number of similar size, similar age office buildings located in the U.S. Ideally, the comparison would also control for personal factors such as job type, gender, and age of respondents.

The major limitations of this study were that it examined the performance of a single building with UFAD and that HVAC operating conditions could not be modified. Thus, we caution against drawing general conclusions about UFAD based on this study. This study did provide unique data suitable for characterizing several aspects of UFAD performance in the study building and provides some evidence of benefits of UFAD that need to be confirmed in other studies. The study also provides a methodology for use in future field studies of UFAD systems.

\section{CONCLUSIONS}

In the study building:

- The air change effectiveness was very close to unity, which is the value typically observed with conventional overhead air supply systems. Thus, the study did not identify an opportunity to save energy by reducing the rate of outdoor air supply because of a high value of air change effectiveness.

- The pollutant removal efficiency for carbon dioxide was $13 \%$ higher that expected with perfectly mixed indoor air, suggesting a 13\% reduction in exposures to occupant generated pollutants.

- $\quad$ The increase in air temperature from locations just above the floor to return grilles was 1 to $2{ }^{\circ} \mathrm{C}$ (2-4 ${ }^{\circ} \mathrm{F}$ ). This amount of thermal stratification could reduce the sensible energy requirements for cooling of outdoor air by approximately $10 \%$.

- The occupants' level of satisfaction with thermal conditions was well above average. This high satisfaction rating could possibly be due, in all or part, to the use of a UFAD system.

The results of this study provide some evidence of energy and IAQ-related benefits of UFAD. Before general conclusions are drawn, the benefits need to be confirmed in other studies.

\section{ACKNOWLEDGMENTS}

This work was supported by the Assistant Secretary for Energy Efficiency and Renewable Energy, Building Technology Program of the U.S. Department of Energy under contract DE-AC03-76SF00098.

\footnotetext{
${ }^{12}$ Average from two surveys in the same building that yielded the same percentile rank within $1 \%$.
} 
We thank Ketakee Kane for her assistance in the data analysis and Fred Bauman and Woody Delp for reviewing a draft of this paper.

\section{REFERENCES}

ASHRAE (2002) Measuring air change effectiveness: AMSI/ASHRAE Standard 129-1997, RA 2002). American Society of Heating, Refrigerating, and Air Conditioning Engineers. Atlanta

ASHRAE (2001) Ventilation for Acceptable Indoor Air Quality, ANSI/ASHRAE Standard 62-2001. American Society of Heating, Refrigerating, and Air Conditioning Engineers. Atlanta

Bauman F. (2003). Underfloor Air Distribution Design Guide. Atlanta: American Society of Heating, Refrigerating, and Air-Conditioning Engineers, Inc., Atlanta. 243 pp.

Bauman F and T. Webster T (2001) Outlook for Underfloor Air Distribution. ASHRAE Journal June 2001, pp. 18-25.

Deru M, Griffith B, Sheffer M, Lau A (2003) Energy Design and Performance Analysis of the Pennsylvania Department of Environmental Protection Cambria Office Building (draft). National Renewable Energy Laboratory. NREL/TP-34931, Golden, Colorado.

Faulkner, D., Fisk, W.J., and Sullivan, D.P. (1993) "Indoor Airflow and Pollutant Removal in a Room With Floor-Based Task Ventilation: Results of Additional Experiments", Building and Environment 30(3), pp. 323-332.

Faulkner D, Fisk WJ, Sullivan DP, Lee SM (2003) Ventilation Efficiencies and Thermal Comfort Results of a Desk-Edge-Mounted Task Ventilation System. Accepted for publication in Indoor Air. LBNL-53798

Fisk, W.J., Prill, R.J., and Seppanen, O. (1988) "A Multi-Tracer Technique for Studying Rates of Ventilation, Air Distribution Patterns, and Air Exchange Efficiencies." Proceedings of Building Systems: Room Air and Air Contaminant Distribution, December 5-8, Univ. of Urbana, IL. Published by ASHRAE, Atlanta, GA.

Fisk, WJ and Faulkner, D. 1992. Air Exchange Effectiveness in Office Buildings: Measurement Techniques and Results, Proceedings of the 1992 International Symposium on Room Air Convection and Ventilation Effectiveness, July 22-24, Tokyo, pp. 213-223, published by ASHRAE, Atlanta, GA.

Fisk, WJ, Faulkner, D, Sullivan, DP, and Bauman, FS. 1997. Air Change Effectiveness and Pollutant Removal Efficiency During Adverse Mixing Conditions, Indoor Air 7(1): 55-63.

Hill, N., Brierley, J., and MacDougall R. (1999) How to Measure Customer Satisfaction, Gower Publishing Ltd.

Huizenga C, Zagreus L, Arens E and Lehrer, D (2003) Measuring Indoor Environmental Quality: A Webbased Occupant Satisfaction Survey. Proceedings of the Greenbuild 2003 Conference, Pittsburgh, PA. http://www.cbe.berkeley.edu/underfloorair/moreInfo.htm

Lehrer, D. and F. Bauman, 2003. Hype vs. Reality: New Research Findings on Underfloor Air Distribution Systems. Proceedings of the Greenbuild 2003 Conference, Pittsburgh PA.

http://www.cbe.berkeley.edu/underfloorair/moreInfo.htm 
Olesen, BW and Seelen, J. 1992. Field Measurements of Air Change Effectiveness using Tracer Gas Techniques, IAQ’92, Environments for People, pp. 301-308, Published by ASHRAE, Atlanta, GA.

Persily, AK. 1986. Ventilation Effectiveness Measurements in an Office Building, Proceedings of IAQ'86, Managing Indoor Air for Health and Energy Conservation, pp. 548-567. Published by ASHRAE, Atlanta, GA.

Persily, AK and Dols, WS. (1989) "Field Measurements of Ventilation and Ventilation Effectiveness in an Office/Library Building”, Indoor Air 1(3): 229-246.

Seppanen, O.A., Fisk, W.J., and Mendell, M.J. (1999) Association of Ventilation Rates and $\mathrm{CO}_{2}$ Concentrations with Health and other Human Responses in Commercial and Institutional Buildings.

Indoor Air 9: 226-252.

Skistad H, Mundt E, Nielsen PV, Hagstrom K, Railio J (2002) Displacement Ventilation in Nonindustrial Premises. REHVA Guidebook. Federation of European Heating and Air-Conditioning Associations. Brussels.

Webster TL, Bauman FS, Reese J and Shi M (2002). Thermal Stratification Performance of Underfloor Air Distribution (UFAD) Systems. Proceedings of the Indoor Air 2002 Conference, vol. 4, pp 260-265. Indoor Air 2002, Inc, Santa Cruz, CA, 


\section{Appendix 1. Relationship of temperature stratification to energy requirements for air conditioning}

This appendix provides the derivations of the expressions for energy savings attributable to thermal stratification in indoor air temperature, i.e., an increase in indoor air temperature with height above the floor. The expressions apply for a building being cooled when the outdoor air temperature exceeds the indoor air temperature. We only consider the energy used for sensible cooling. The basis for the energy savings estimates is a comparison of the heat that must be removed by the building's air conditioning system in two buildings. The first building has no thermal stratification. The second building has thermal stratification. We will assume that the first building, denoted as B1, has a conventional overhead air distribution system and that the second building, denoted as B2, has an underfloor air distribution (UFAD) system; however, the savings estimates remain valid regardless of the type of air distribution. An important distinction of buildings with UFAD systems, such as B2, is that substantial heat is transferred from the occupied space through the suspended floor to the supply air flowing beneath the suspended floor.

The two buildings are assumed identical with respect to the rates of: a) internal heat generation; b) heat conduction through the building envelope, c) solar heat gain, e) air flows in HVAC airstreams, f) fan energy use ${ }^{13}$. For simplicity, we assume that there is no air leakage through the building envelope, i.e., all air enters and exits the building via the HVAC system and that the return air temperature does not increase after it passes through the return air grilles. We also assume that the coefficient of performance of the air conditioner is the same in the two buildings, despite a slightly higher supply air temperature in the building with thermal stratification.

There is one additional key but reasonable assumption - the average air temperature in the occupied zone, denoted $\mathrm{T}_{\mathrm{Oz}}$, must be the same in the two buildings in order to maintain the same level of thermal comfort $^{14}$. In the building without thermal stratification, $\mathrm{T}_{\mathrm{oz}}$ will be identical to the return air temperature $\left(\mathrm{T}_{\mathrm{R}}\right)$. In the building with thermal stratification, $\mathrm{T}_{\mathrm{R}}$ will exceed $\mathrm{T}_{\mathrm{oz}}$ by an amount, denoted $\Delta \mathrm{T}$.

The terms used in the derivation are defined in the following table.

Table A1. Terms and variable names.

\begin{tabular}{|l|l|l|}
\hline Term & $\begin{array}{l}\text { Variable } \\
\text { name in } \mathrm{B} 1\end{array}$ & $\begin{array}{l}\text { Variable } \\
\text { name in B2 }\end{array}$ \\
\hline temperature of outdoor air (OA) & $\mathrm{T}_{\mathrm{OA}}$ & $\mathrm{T}_{\mathrm{OA}}$ \\
\hline temperature of air exiting cooling coil & $\mathrm{T}_{\mathrm{Cc}}$ & $\mathrm{T} 2_{\mathrm{Cc}}$ \\
\hline temperature of air exiting supply fan located downstream of cooling coil & $\mathrm{T}_{\mathrm{FAN}}$ & $\mathrm{T} 2_{\mathrm{FAN}}$ \\
\hline temperature of air entering occupied space through supply air diffuser & $\mathrm{T}_{\mathrm{S}}$ & $\mathrm{T} 2_{\mathrm{S}}$ \\
\hline temperature of air exiting occupied space & $\mathrm{T}_{\mathrm{R}}$ & $\mathrm{T} 2_{\mathrm{R}}$ \\
\hline average temperature in occupied zone & $\mathrm{T} 1_{\mathrm{OZ}}$ & $\mathrm{T} 2_{\mathrm{OZ}}$ \\
\hline $\begin{array}{l}\text { temperature of air exiting occupied space minus average temperature in } \\
\text { occupied zone }\end{array}$ & $\Delta \mathrm{T}$ & ------ \\
\hline total heat removal by the air conditioning (AC) unit & $\mathrm{Q}_{\mathrm{AC}}$ & $\mathrm{Q}_{\mathrm{AC}}$ \\
\hline rate of heat release by supply fan & $\mathrm{Q}_{\mathrm{FAN}}$ & $\mathrm{Q}_{\mathrm{FAN}}$ \\
\hline $\begin{array}{l}\text { sum of all rates of heat gains in the building excluding heat produced by } \\
\text { the supply fan and the heat associated with the entry of outdoor air }\end{array}$ & $\mathrm{Q}_{\mathrm{GAIN}}$ & $\mathrm{Q}_{\mathrm{GAIN}}$ \\
\hline heat load from entering outdoor air & $\mathrm{Q}_{\mathrm{OA}}$ & $\mathrm{Q}_{\mathrm{OA}}$ \\
\hline
\end{tabular}

\footnotetext{
${ }^{13}$ If fan energy use is reduced in the building with UFAD because of reductions in airflow resistance with UFAD, there will be larger reductions in the sensible cooling load and larger energy savings.

${ }^{14}$ The influence of the thermal gradient on thermal comfort is neglected.
} 


\begin{tabular}{|l|l|l|}
\hline $\begin{array}{l}\text { rate of heat transfer through the suspended floor of a UFAD system from } \\
\text { the occupied space to the supply air plenum }\end{array}$ & Q & \\
\hline rate of heat transfer to the air flowing through the occupied spaces & $\mathrm{Q}_{\text {ROOM }}$ & $\mathrm{Q}_{\mathrm{ROOM}}$ \\
\hline product of mass flow rate and specific heat of supply airstream & $\mathrm{M}$ & $\mathrm{M}$ \\
\hline fraction of outdoor air in supply airstream & $\mathrm{X}$ & $\mathrm{X}$ \\
\hline
\end{tabular}

From an energy balance for the air flowing through the cooling coil:

$$
\begin{aligned}
& Q 1_{A C}=M X\left(T_{\text {OUT }}-T 1_{C C}\right)+M(1-X)\left(T 1_{R}-T 1_{C C}\right) \\
& Q 2_{A C}=M X\left(T_{\text {OUT }}-T 2_{C C}\right)+M(1-X)\left(T 2_{R}-T 2_{C C}\right)
\end{aligned}
$$

The first term on the right side of these two prior equations represents the heat removed from the outdoor air as it flows through the cooling coil and the second term represents the heat removed from recirculated indoor air as it flows through the cooling coil.

From an energy balance, the rate of heat removal from the incoming outdoor air to bring this air to the return air temperature is

$$
\begin{aligned}
& Q 1_{O A}=M X\left(T_{\text {OUT }}-T 1_{R}\right) \\
& Q 2_{O A}=M X\left(T_{\text {OUT }}-T 2_{R}\right)
\end{aligned}
$$

An energy balance for air as it flows through the occupied space yields

$$
\begin{aligned}
& Q 1_{\text {ROOM }}=M\left(T 1_{R}-T 1_{S}\right) \\
& Q 2_{\text {ROOM }}=M\left(T 2_{R}-T 2_{S}\right)
\end{aligned}
$$

From an energy balance across the supply fan

$$
\begin{aligned}
& Q_{F A N}=M\left(T 1_{F A N}-T 1_{C C}\right) \\
& Q_{F A N}=M\left(T 2_{F A N}-T 2_{C C}\right)
\end{aligned}
$$

For the air flowing through the underfloor supply air plenum in B2, an energy balance yields

$$
Q_{F L O O R}=M\left(T 2_{S}-T 2_{F A N}\right)
$$

while in B2

$T 1_{S}=T 1_{F A N}$

In B1, the total heat gain to the supply air after it exits the cooling coil is

$$
Q_{\text {GAIN }}=Q_{F A N}+Q 1_{R O O M}
$$


while in building 2

$$
Q_{\text {GAIN }}=Q_{F A N}+Q 2_{F L O O R}+Q 2_{R O O M}
$$

Since $\mathrm{Q}_{\mathrm{GAIN}}$ is the same in both buildings

$$
Q_{F A N}+Q 1_{R O O M}=Q_{F A N}+Q 2_{F L O O R}+Q 2_{R O O M}
$$

Substituting prior equations for each heat transfer rate yields

$$
M\left(T 1_{F A N}-T 1_{C C}\right)+\left(M\left(T 1_{R}-T 1_{S}\right)=M\left(T 2_{F A N}-T 2_{C C}\right)+M\left(T 2_{S}-T 2_{F A N}\right)+M\left(T 2_{R}-T 2_{S}\right)\right.
$$

Because $T 1_{R}$ equals $T_{\mathrm{OZ}}$ and $T 2_{R}$ equals $\mathrm{T}_{\mathrm{oz}}+\Delta \mathrm{T}, \mathrm{T} 1_{\mathrm{FAN}}$ equals $\mathrm{T} 1_{\mathrm{S}}$, and $\mathrm{M}$ is the same for both buildings, simplifying the prior equation results in the following

$$
T 2_{C C}=T 1_{C C}+\Delta T
$$

Therefore, with thermal stratification the temperature of air exiting the cooling coil can be increased by $\Delta \mathrm{T}$.

Now, combining equations $A 1, A 2$, and A16, and applying $T 1_{R}=T_{O z}$ plus $T 2_{R}=T_{O Z}+\Delta T$, we derive the following simple equation ${ }^{15}$ for energy savings

$$
Q 1_{A C}-Q 2_{A C}=M X \Delta T
$$

Since the energy used for air conditioning is directly proportional to the heat removal provided by the air conditioned, we can calculate energy savings fractions as follows

$$
\begin{aligned}
& S F_{O A}=\frac{Q 1_{A C}-Q 2_{A C}}{Q 1_{O A}}=\frac{M X \Delta T}{M X\left(T_{O U T}-T 1_{R}\right)}=\frac{M X \Delta T}{M X\left(T_{O U T}-T_{O Z}\right)} \\
& S F_{\text {TOTAL }}=\frac{Q 1_{A C}-Q 2_{A C}}{Q 1_{A C}}=\frac{M X \Delta T}{M X\left(T_{O U T}-T 1_{C C}\right)+M(1-X)\left(T 1_{R}-T 1_{C C}\right)}
\end{aligned}
$$

The first of these savings fractions normalizes the energy savings by the energy required for sensible cooling of outdoor air in a building with a conventional overhead air distribution system. The second savings fraction normalizes the energy savings by the total energy required for sensible energy removal in a building with a conventional overhead air distribution system. The prior discussion section provides example values of each savings fraction and discusses how the savings fractions will change when the air conditioning system provides dehumidification.

\footnotetext{
${ }^{15}$ The same energy savings estimate can be derived by considering a whole-building energy balance. With thermal stratification, the temperature of air exhausted to outdoors by the HVAC system is increased by $\Delta \mathrm{T}$, thus, the heat rejection to outdoors with the exhaust air is increased by $\mathrm{MX} \Delta \mathrm{T}$, reducing the load on the air conditioner by the same amount.
} 